\author{
UNITED STATES \\ DEPARTMENT OF THE INTERIOR \\ U.S. GEOLOGICAL SURVEY \\ RADAR REFLECTOR DETECTION \\ By Neil L. Falcone
}

Open-File Report 84-879

Reston, Virginia

1985 



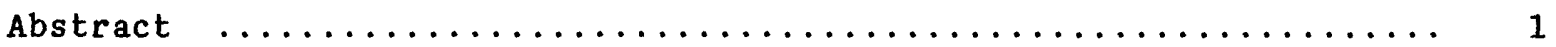

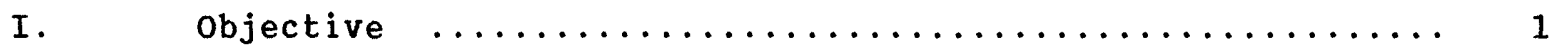

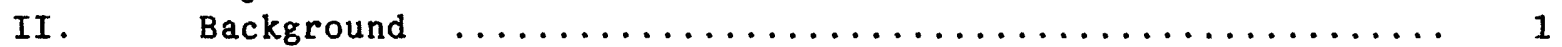

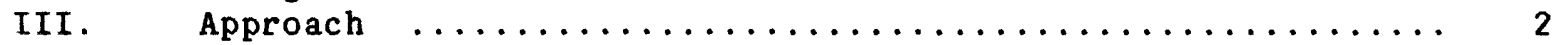

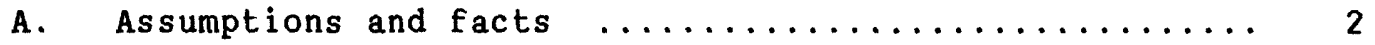

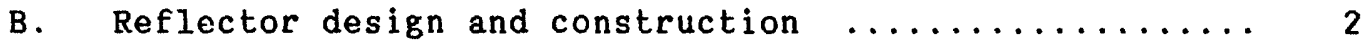

C. Data acquisition - system parameters $\ldots \ldots \ldots \ldots \ldots \ldots . \ldots \ldots$

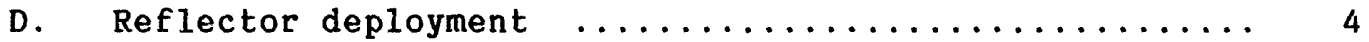

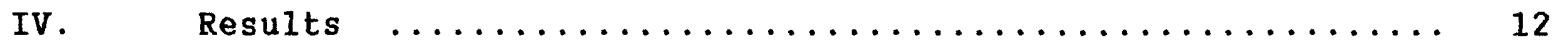

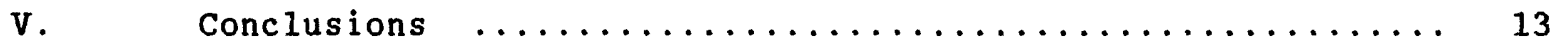

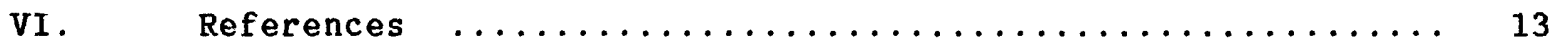

\section{ILLUSTRATIONS}

Figure 1. North-south flight lines covering the central

Appalachian project area $\ldots \ldots \ldots \ldots \ldots \ldots \ldots \ldots \ldots$

2. The near-range radar geometry showing the designated depression angle range and the ground swath 1 ine separation with overlap for the image strips ......

3. Approximate locations and description of reflectors as shown on 7.5-minute quadrangles of the

Appalachian test area $\ldots \ldots \ldots \ldots \ldots \ldots \ldots \ldots \ldots \ldots 6$

4A. An aluminum single unit triangular trihedral corner radar reflector set up on angle iron supports ..... 7

4B. An aluminum stacked unit triangular trihedral corner radar reflector set up on angle iron supports $\ldots \ldots .8$

5. A single unit triangular trihedral corner

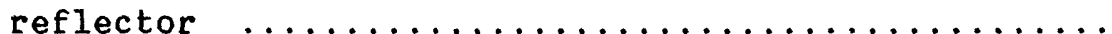

6A. Precise positions of reflectors in the Smithsonian Park plotted on the 7.5-minute map of Front Royal, Virginia, with corresponding descriptive photograph

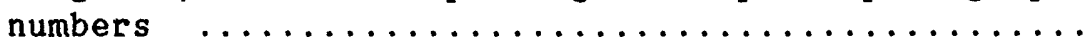

6B. Precise positions of reflectors in the Smithsonian Park marked on the SLAR imagery $\ldots \ldots \ldots \ldots \ldots \ldots$

TABLES

Table 1. Geographic positions, sizes, and configuration of reflectors as computed from 7.5-minute map UTM coordinates 


\title{
RADAR REFLECTOR DETECTION
}

\author{
By Neil L. Falcone \\ U.S. Geological Survey \\ 521 National Center \\ Reston, Virginia 22092
}

\begin{abstract}
The U.S. Geological Survey (USGS) has tested the detectability of various sizes and combinations of aluminum trihedral (cornercube) reflectors by side-looking airborne radar (SLAR). The influence of system characteristics, mapping requirements, and SLAR image products indicate that radar reflectors can be used to detect specific ground positions on SLAR imagery, and that such reflectors could prove useful in applying geometric analysis of SLAR imagery and geometric control in the creation of SLAR image mosaics.
\end{abstract}

\section{OBJECTIVE}

The objective of this study was to test the detectability of a variety of sizes and combinations of aluminum trihedral (cornercube) reflectors by side-looking airborne radar (SLAR).

\section{BACKGROUND}

The U.S. Geological Survey (USGS) is conducting research in the use of SLAR imagery for cartographic and geological purposes and this report summarizes a part of the study of the cartographic use of radar for topographic mapping.

A contract to acquire imagery for the Synthetic Aperture Radar (SAR) System and Survey was awarded in 1982 by the USGS to the Aero Service Corporation of Houston, Tex. (contract number 14-08-0001-21382). This project involved the purchase, acquisition, and evaluation of Synthetic Aperture SLAR data within Alaska and the contiguous United States. As part of the project, the USGS studied whether prepositioned targets would image on radar so that they could prove useful in the geometric analysis of image products.

Publication authorized by the Director, U.S. Geological Survey, on November 26, 1984. Any use of trade names and trademarks in this publication is for identification purposes only and does not constitute endorsement by the U.S. Geological Survey. 
Previous investigations of radar reflector detection have resulted in little documentation by researchers in either the public or private sectors. Literature searches of numerous publications revealed brief statements relating specifically to targets and reflectors but there were no substantial comments. Only Levine's, 1960 text, "Radargrammetry", was found to contain information about targets for use with imaging radar. There is generally a distinction made between a reflector and a target; a reflector is an object which gives a strong radar signal return and can be used to identify ground locations. A target refers to a larger object such as a ship or an aircraft.

\section{APPROACH \\ A. Assumptions and Facts}

There are three types of radar reflectors that are known to have applications for imaging radar systems. They are the Lunenberg lens, cylindrical and trihedral reflectors. These reflectors have varied uses, such as measuring amplitude of signal return, performing resolution studies, and the geometric testing of imagery.

Lunenberg lens reflectors consist of concentric spherical cells and are expensive to produce. Cylindrical reflectors can only be used for special applications, such as modeling grass and some types of vegetation, and were thus considered unsuitable for this project. The primary objective of the project was to determine the detectability of an object, thus a trihedral cornercube reflector would, if used properly, yield a true point return and a relatively strong signal return. Each trihedral cornercube reflector was positioned in an isolated area where the intensity of its return signal would be most prominent. Trihedral cornercube reflectors were also considered the most practical because they could be made locally and placed in a project area convenient to USGS. Considering these factors, trihedral cornercube reflectors were selected for this project.

\section{B. Reflector Design and Construction}

Several sheets of one-quarter-inch-thick sheet aluminum having a polished surface were used for the reflector construction. Seventeen triangular trihedral corner reflectors were constructed by cutting these sheets into right isosceles triangles that were assembled into a cornercube configuration. The reflectors ranged in height from 1- to 4-foot size single units, and from 2- to 4-foot size stacked units composed of multiple 1-foot size reflectors. The reflectors were prepared in August 1982.

\section{Data Acquisition - System Parameters}

SLAR imagery was acquired of several areas of the contiguous United States in 1982. The Central Appalachian Project Area was selected for the radar reflector detection project because of its proximity to the USGS in Reston, (fig. 1). The area for potential reflector deployment was located in the northeast corner of the Charlottesville, 1:250,000-scale quadrangle and the southeast corner of the Cumberland, 1:250,000-scale quadrangle. 


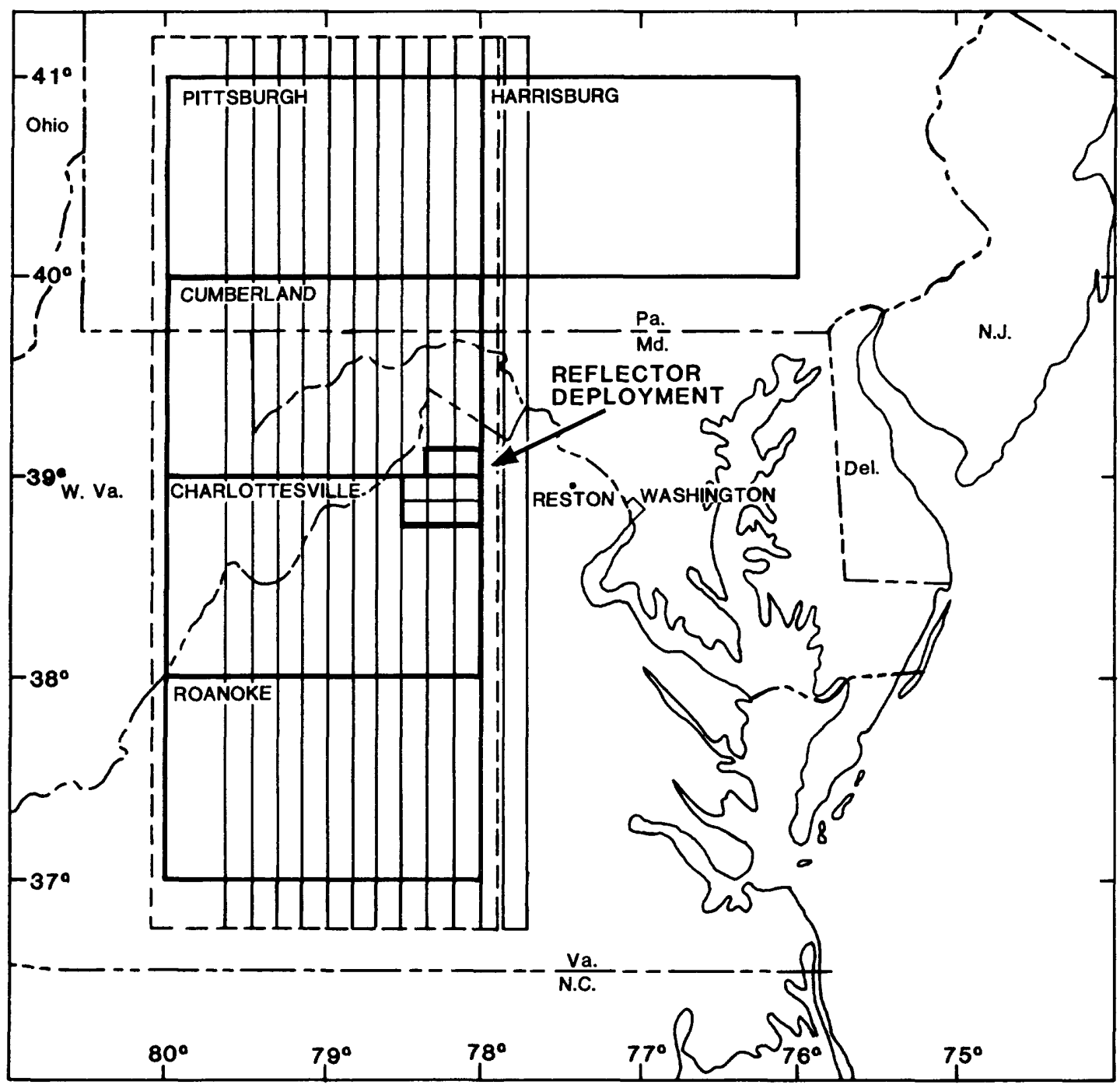

Figure 1.-- North-south flight lines covering the Central Appalachian Project Area.

A reconnaissance survey was made in June, 1982, in the proposed project area; twenty reflector areas were selected. Three sites proved to be inappropriate and were dropped from the study. A field book was compiled containing the locations on 7.5-minute USGS topographic maps of the project area, site descriptions, and photographs taken of surrounding areas for potential reflector deployment. The SLAR imagery was to be flown in north-south flightlines with a west-look direction. Clinometer readings were made at each site to measure the minimum vertical angle of surrounding features which might interfere with the radar signals reaching the reflectors. One area selected for potential reflector deployment was near Front Royal, Virginia on the property of the Smithsonian Institution Zoological Park. This 
area consisted predominantly of sloping open fields and sparse foilage along with a few scattered buildings in a fence--enclosed environment. The specific locations were first selected from 7.5-minute topographic quadrangle maps; the fundamental site selection criterion was to locate sites having terrain exhibiting a clear line-of sight to the radar. It was also recognized that reflectors placed on secured property such as the park would be relatively free from the possibilities of theft or vandalism before the imagery could be acquired.

Data acquisition of SLAR imagery was carried out with a Caravelle twin jet aircraft flying at 12,000 meters. The radar system employed was a Goodyear Electronic Mapping system (GEMS) X-Band SLAR operating in an approximate band width of $3 \mathrm{~cm}$. The GEMS antenna array projects a beam to the left or right of the aircraft, which permits imagery to be acquired along the ground range in the west-look direction from either a north or a south aircraft heading.

The GEMS system was designed specifically for mapping rather than reconnaissance missions. The system has a total imaging range of more than $50 \mathrm{~km}$, although only the near-range imagery was used for reflector detection. For the Central Appalachian area, near-range geometry resulted in depression angles between $33^{\circ}$ and $20.3^{\circ}$ (fig. 2). The total image swath was $37 \mathrm{~km}$, producing two 20 $\mathrm{km}$ ground range strip coverages in near- and far-range channels with a $5-\mathrm{km}$ overlap between strips. The $14 \mathrm{~km}$ near-range geometry and line separation resulted from the depression angle range of $33^{\circ}$ to $20.3^{\circ}$

\section{Reflector Deployment}

The USGS was informed on September 5, 1982 that the SLAR imagery was to be flown over the Central Appalachian test area during the week of September 13 to 18. Seventeen aluminum trihedral reflector units were deployed in the test area on September 10 and 11 (fig. 3). Each reflector was placed at the sites predetermined from the reconnaissance survey and deployed near public thoroughfares in areas where natural and manmade features were combined with varying terrain slope elevation. These positions were selected to offer different surroundings for the reflector(s); this, in turn could influence the strength of a radar signal recorded for a particular reflector. Descriptions were recorded and photographs were taken at each site.

Each reflector was set up on angle iron supports 3-4 feet off the ground, with the reflector aligned by compass facing directly east (figs. 4A and 4B ). This procedure permitted the intersection of the SLAR west-look beam to enter the corner of the reflector to produce a signal response returning to the antenna array of the (GEMS) system (fig. 5). Six of the larger reflectors-three single units, $(2,3$, and 4 feet in size) and three stacked units $(2,3$, and 4 feet in size)-were placed on the Smithsonian Park property (fig. 6A). The remaining 11 reflectors were deployed in areas predetermined from the reconnaissance survey covering the 7.5-minute quadrangles comprising the reflector project area (fig. 3). All reflector positions were precisely marked on the 7.5-minute maps and geographic positions of each reflector were computed from the map and recorded (table 1).

All 17 reflectors were retrieved on September 22-23, 1982 upon confirmation from Aero Service Corporation that the Appalachian Test area had been completely covered with SLAR imagery. None of the reflectors had been disturbed during deployment, and were therefore presumed imaged. 

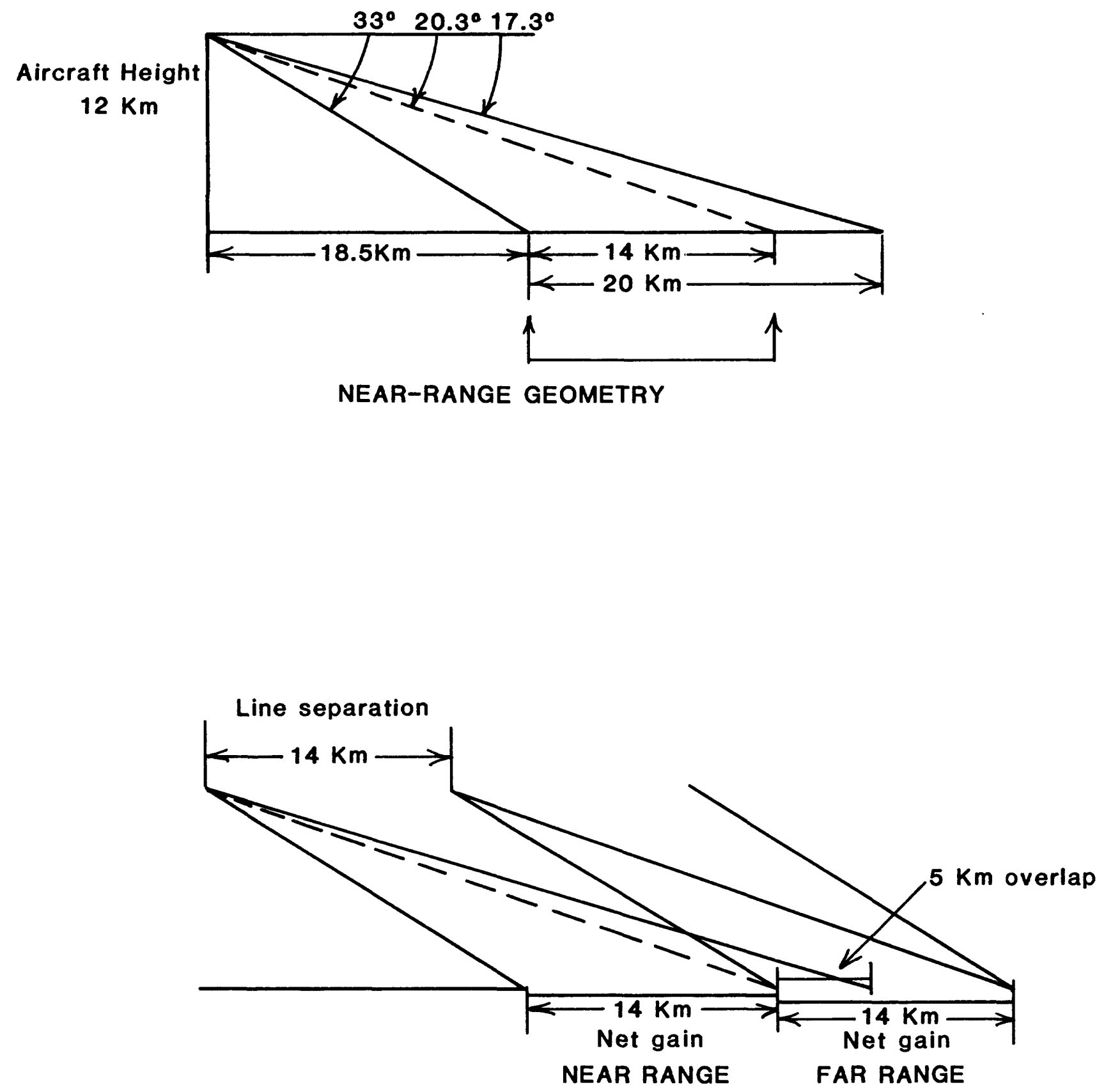

Figure 2.--The near-range geometry showing the designated depression angle range and the ground swath line separation with overlap for the image strips. 


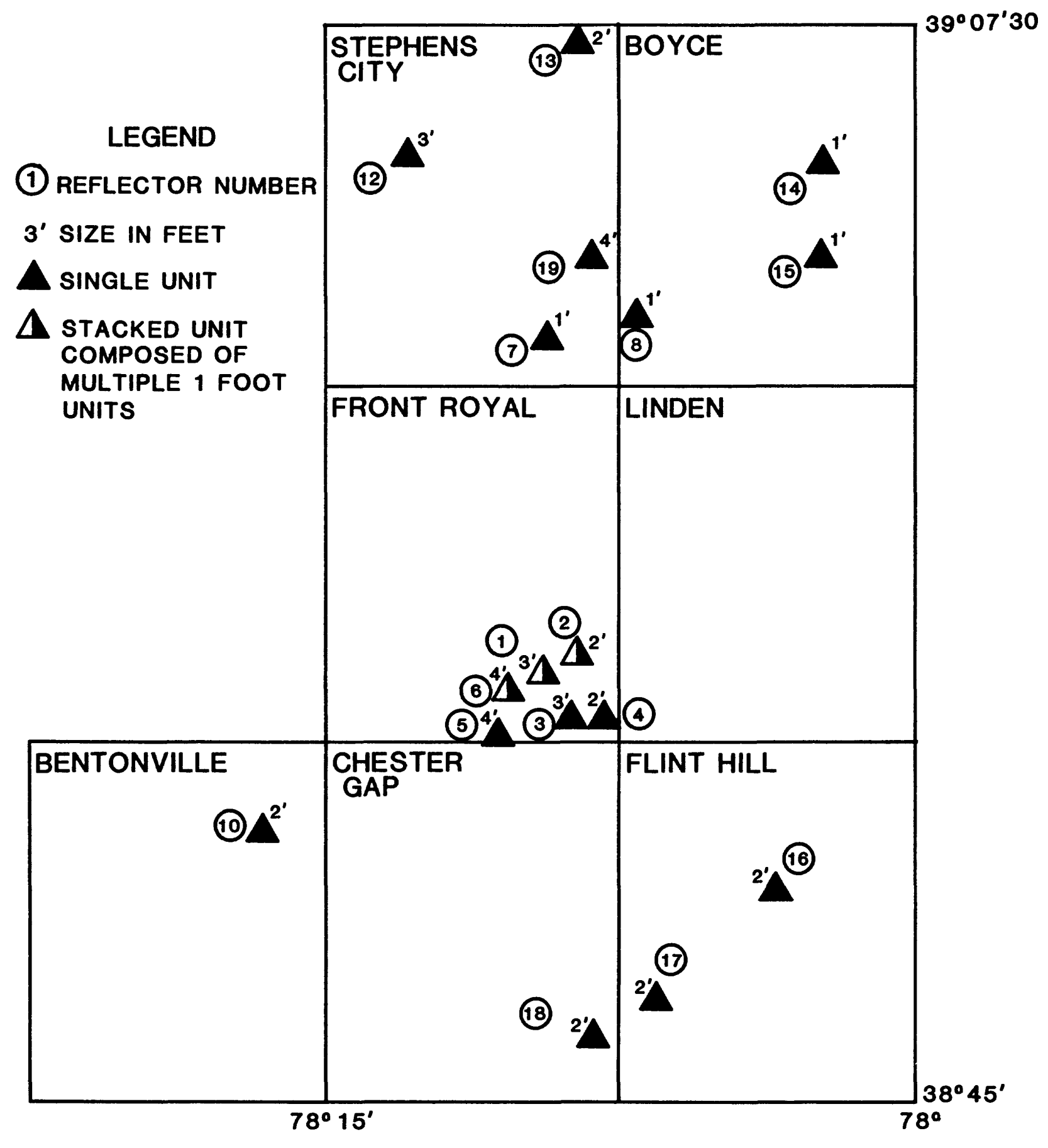

Figure 3.--Approximate locations and description of reflectors as shown on 7.5-minute quadrangles of the Appalachian test area. 

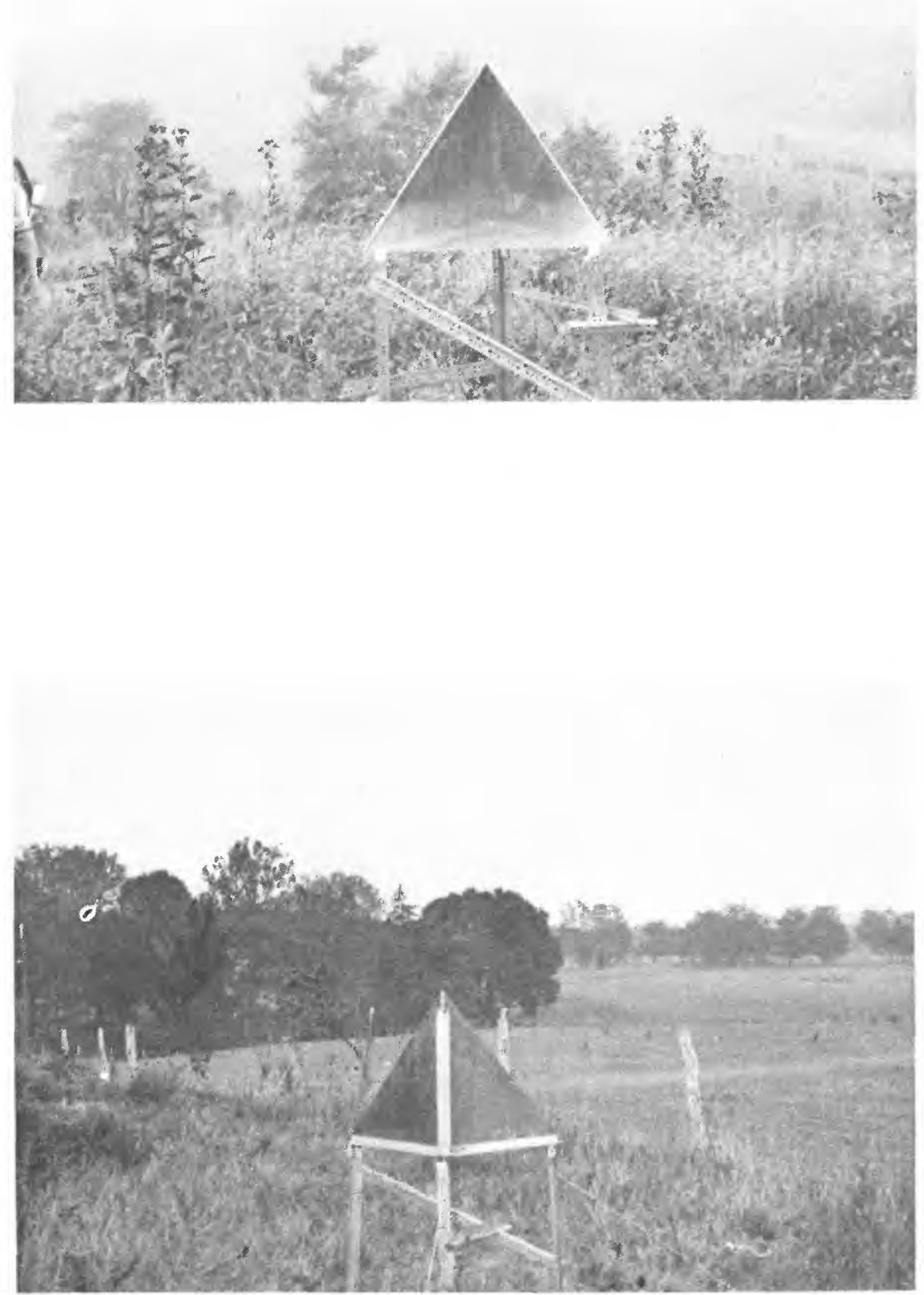

Figure 4A.--An aluminum single unit triangular trihedral corner radar reflector set up on angle iron supports. 

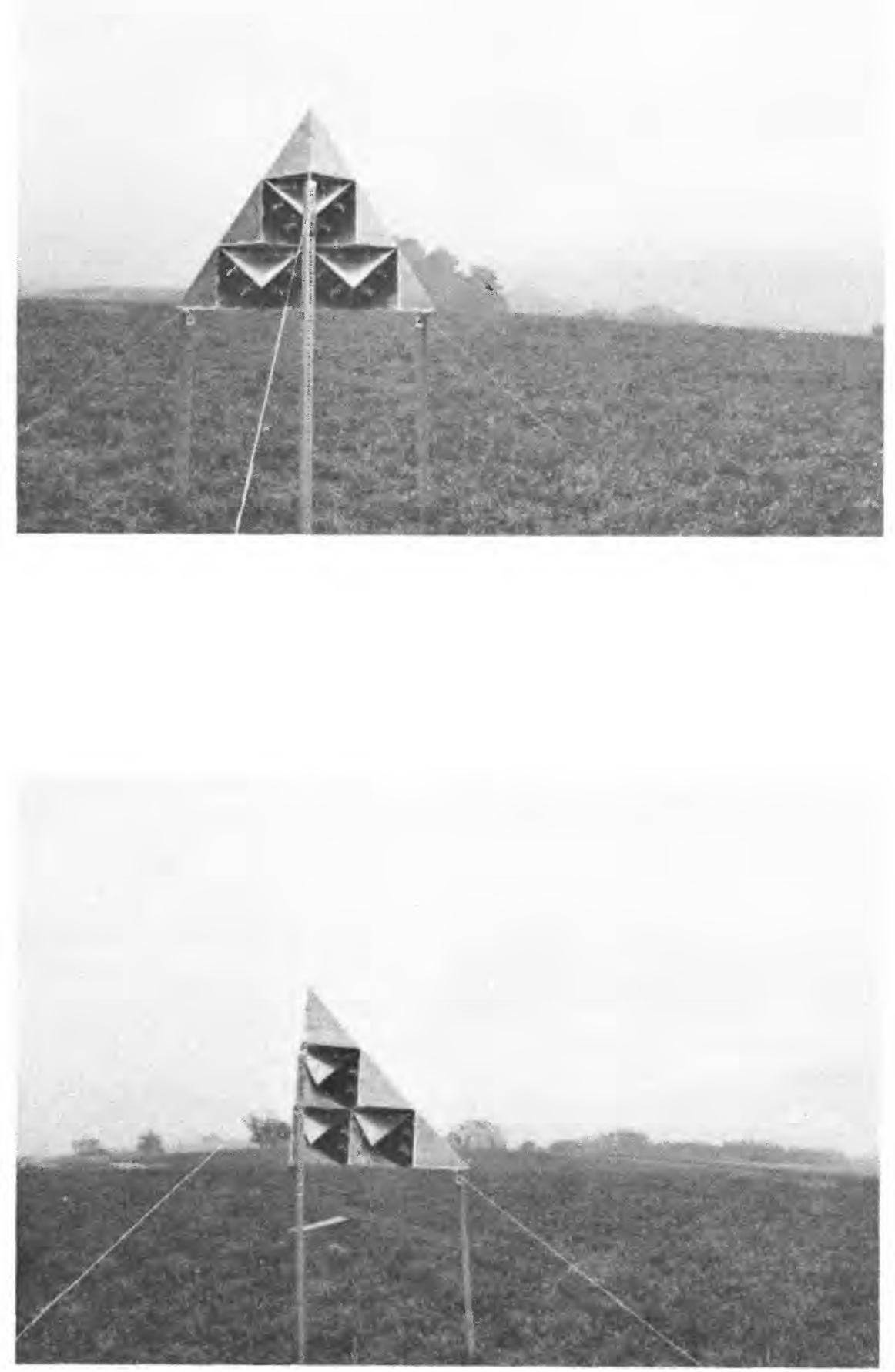

Figure 4B.- An aluminum stacked unit triangular trihedral corner radar reflector set up on angle iron supports. 


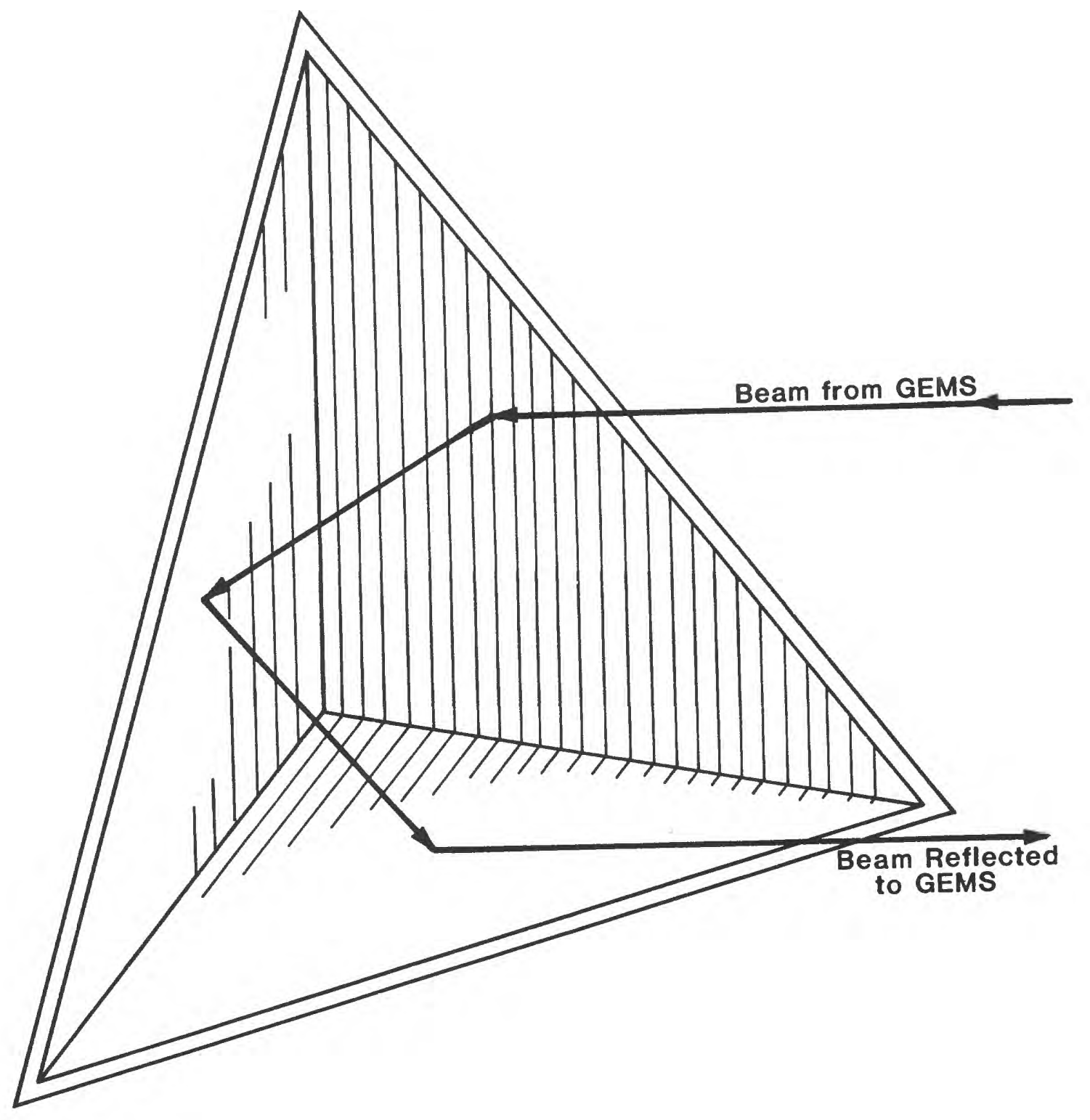

Figure 5.--Triangular trihedral corner reflector. 


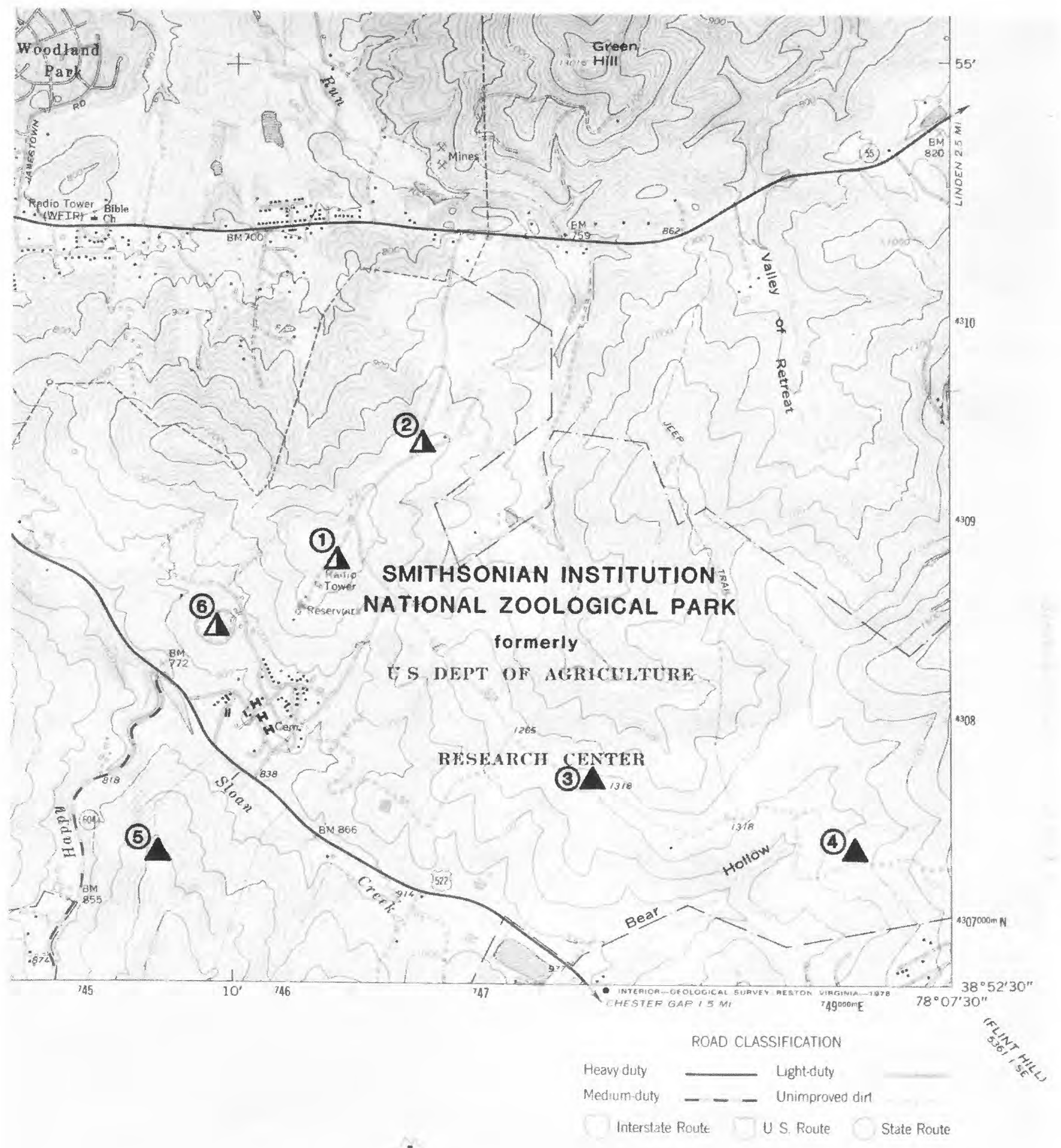

FRONT ROYAL, VA.

N3852 5 - W78075/75

Figure 6A.--Precise positions of reflectors in the Smithsonian Park plotted on the 7.5-minute map of Front Royal, Virginia, with corresponding reflector numbers. 


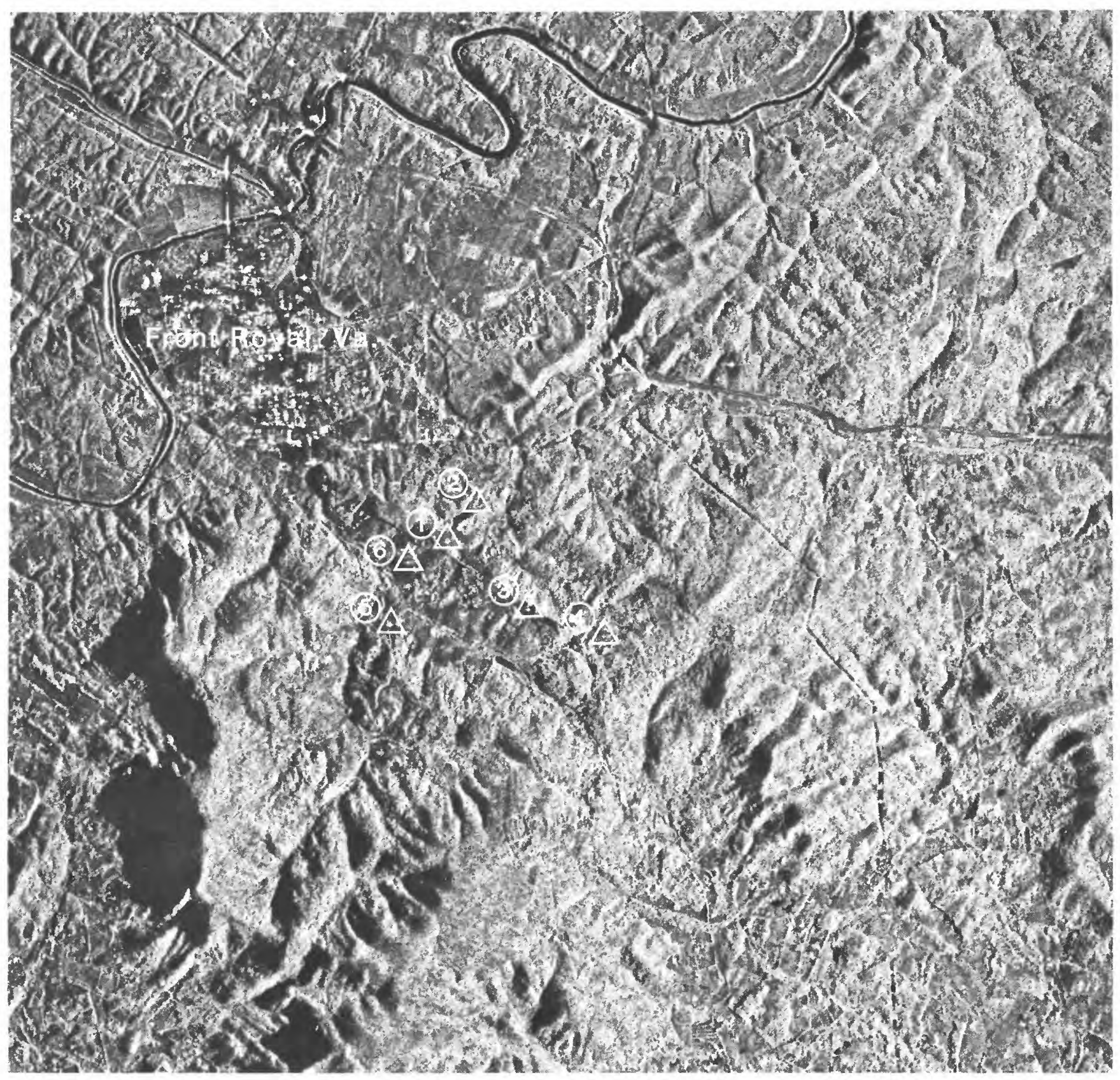

Figure 6B. - Precise positions of reflectors in the Smithsonian Park marked on the SLAR imagery. 
Table 1.-Geographic positions, sizes, and configuration of reflectors as computed from 7.5-minute map rectangular (UTM) coordinates.

Target size

Reflector no. ${ }^{1}$ Latitude __ Longitude ___feet) _ _ Configuration

$\begin{array}{ccccl}1 & 38^{\circ} 53^{\prime} 38^{\prime \prime} & 78^{\circ} 09^{\prime} 39^{\prime \prime} & 3^{\prime} & \text { Stacked } \\ 2 & 38^{\circ} 53^{\prime} 56^{\prime \prime} & 78^{\circ} 09^{\prime} 21^{\prime \prime} & 2^{\prime} & \text { Stacked } \\ 3 & 38^{\circ} 53^{\prime} 03^{\prime \prime} & 78^{\circ} 08^{\prime} 45^{\prime \prime} & 3^{\prime} & \text { Single Unit } \\ 4 & 38^{\circ} 52^{\prime} 50^{\prime \prime} & 78^{\circ} 07^{\prime} 51^{\prime \prime} & 2^{\prime} & \text { Single Unit } \\ 5 & 38^{\circ} 52^{\prime} 50^{\prime \prime} & 78^{\circ} 10^{\prime} 17^{\prime \prime} & 4^{\prime} & \text { Single Unit } \\ 6 & 38^{\circ} 53^{\prime} 27^{\prime \prime} & 78^{\circ} 10^{\prime} 04^{\prime \prime} & 4^{\prime} & \text { Stacked } \\ 7 & 39^{\circ} 00^{\prime} 21^{\prime \prime} & 78^{\circ} 09^{\prime} 50^{\prime \prime} & 1^{\prime} & \text { Single Unit } \\ 8 & 39^{\circ} 00^{\prime} 32^{\prime \prime} & 78^{\circ} 07^{\prime} 55^{\prime \prime} & 1^{\prime} & \text { Single Unit } \\ 10^{2} & 38^{\circ} 50^{\prime} 11^{\prime \prime} & 78^{\circ} 18^{\prime} 22^{\prime \prime} & 2^{\prime} & \text { Single Unit } \\ 12 & 39^{\circ} 07^{\prime} 10^{\prime \prime} & 78^{\circ} 11^{\prime} 25^{\prime \prime} & 3^{\prime} & \text { Single Unit } \\ 13 & 39^{\circ} 06^{\prime} 37^{\prime \prime} & 78^{\circ} 08^{\prime} 52^{\prime \prime} & 2^{\prime} & \text { Single Unit } \\ 14 & 39^{\circ} 04^{\prime} 42^{\prime \prime} & 78^{\circ} 02^{\prime} 00^{\prime \prime} & 1^{\prime} & \text { Single Unit } \\ 15 & 39^{\circ} 02^{\prime} 40^{\prime \prime} & 78^{\circ} 02^{\prime} 06^{\prime \prime} & 1^{\prime} & \text { Single Unit } \\ 16 & 38^{\circ} 49^{\prime} 33^{\prime \prime} & 78^{\circ} 03^{\prime} 20^{\prime \prime} & 2^{\prime} & \text { Single Unit } \\ 17 & 38^{\circ} 46^{\prime} 54^{\prime \prime} & 78^{\circ} 07^{\prime} 12^{\prime \prime} & 2^{\prime} & \text { Single Unit } \\ 18 & 38^{\circ} 45^{\prime} 18^{\prime \prime} & 78^{\circ} 07^{\prime} 48^{\prime \prime} & 2^{\prime} & \text { Single Unit } \\ 19 & 39^{\circ} 03^{\prime} 05^{\prime \prime} & 78^{\circ} 08^{\prime} 16^{\prime \prime} & 4^{\prime} & \text { Single Unit }\end{array}$

1 Twenty location sites were initially selected. Of these 20 , only 17 were actually used; location sites for reflectors 9,11 , and 20 proved to be inappropriate.

2 Reflector was outside radar image swath.

\section{RESULTS}

The first photographic paper prints of strip imagery at 1:400,000-scale covering the Central Appalachian test area were received in January, 1983. Initial inspection, using a magnifying lens, of a paper print of flight-line 120 near-range image indicated that the 3-and 4-foot reflectors in the Smithsonian Park could be detected as small speckled bright spots. Reflector number 10 in the Bentonville quadrangle was found to be off the image strip leaving 16 reflectors imaged for possible detection. The paper prints were used only for initial inspection to insure that reflector positions had been imaged by the radar. However, when the paper print was magnified it appeared grainy, making it necessary to use a film transparency as a more reliable source of detection.

A film positive transparency made from original film negatives of flight strip 120 (near range) at 1:400,000-scale was supplied in February, 1983. The film was placed in a Kern monocomparator, which permitted 28-times magnification without 
image resolution loss. The 3- and 4 foot reflectors could again be identified throughout the test area. The two-foot reflectors (2 and 4 ) in the Smithsonian Park imaged as smaller speckled bright spots. The clarity, in the latter case, was complicated by the proximity of other nearby manmade and natural objects intersecting, such as a vertical wall of isolated buildings, and a horizontal surface which would also appear as a bright spot. To insure that the reflectors were being correctly identified, the positions of the reflectors shown on the map (fig. 6A) were compared to the imaged bright spots on the SLAR image (fig. 6B).

In the Stephens City 7.5-minute quadrangle test area, it was seen that the 3-foot number 12 and the 4-foot number 19 reflectors in single units could be identified on the film strip through magnification. These reflectors were purposely deployed in areas with surrounding manmade objects to determine their detectability. Reflector number 12 was positioned approximately 10 yards east of a 4-lane divided highway and was easily identified on the film image, although there was significant signal return appearing as bright strips from the highway. Reflector number 19 was positioned in an open field approximately 100 yards from the nearest of five buildings, some having metal roofs. This reflector was seen on the film image, and was precisely located along with the five buildings appearing as a pattern of bright spots, by comparing their placement to the 7.5 -minute quadrangle. It was determined that 1 - and 2-foot single-unit reflectors throughout the project test area and the 2-foot stacked unit in the park could not be clearly identified because of their smaller signature causing them to resemble other small unknown objects nearby.

\section{CONCLUSIONS}

The radar return generated from a surface such as an aluminum trihedral corner reflector recorded on an image indicated that such an object has the potential to be used for some forms of SLAR image mapping. It can be seen from the results of the SLAR image evaluation that radar reflectors can be used to detect specific ground control points that normally would not image on SLAR imagery. Such reflectors may prove useful in conducting geometric analysis of SLAR imagery and for geometric control in the creation of SLAR image mosaics. The results also showed that the larger (3-foot and 4-foot) aluminum reflectors could be clearly identified even though signal returns from various other objects also appeared as bright spots on the SLAR imagery.

The primary purpose for this project was to determine the detectability of aluminum trihedral reflectors. Because of limited resources, only a basic qualitative approach was considered at this time. A study of the detection of reflectors from SLAR image data in digital form for a quantitative evaluation of radar reflector detection would be desireable.

\section{REFERENCES}

Aero Service Coporation, Technical Proposal for Airborne Synthetic Aperture Radar (SAR) Survey of Project Areas in the United States of America, p. 39-40.

Devine, D., 1960, Radargrammetry: McGraw-Hill, p. 209-215.

Huynen, J.R., 1958, Theory and design of a class of Lunenburg Lenses: IRE Wescon Conv. Record, part 1, August 19-22, p. 219-230.

Manual of Remote Sensing, American Society of Photogrammetry, 1st Edition, 1975, p. 141-142. 